\title{
Cuerpo, desnudez y silencio en La mujer desnuda de Armonía Somers*
}

\author{
Body, nudity and silence in La mujer desnuda (the naked \\ woman) by Armonía Somers
}

Agustina Ibañez**

\section{RESUMEN}

El presente artículo estudia el binomio cuerpo-desnudez en $L a$ Palabras clave: mujer desnuda (1950) de la escritora uruguaya Armonía Somers nueva narrativa (1914-1994). El objetivo es demostrar que en esta novela el cuerpo-femenino-desnudo se configura como un espacio desde el cual se cuestiona la relación de dominación de los hombres sobre las mujeres y se quiebra la supremacía que tanto la filosofía como la religión le han otorgado a la Razón, al intelecto o al chilena, política de los afectos, clase social, corporalidades, posdictadura. espíritu por sobre lo somático. El recorrido de lectura trazado permitirá observar que Somers construye la corporalidad desde el silencio, resignificando ese sin-lugar que la carne ha tenido en la tradición filosófica.

\section{SUMMARY}

This article studies the body-nudity binomial in La mujer desnuKeywords: $d a$ (In English: The Naked Woman) (1950) by Uruguayan writer Somers Harmony, Armonía Somers (1914-1994). The objective is to show that in this novel the nude-female-body is configured as a space from which the relationship of male domination over women is questioned. The supremacy that both philosophy and religion have female body, The naked woman, Uruguayan literature. given to Reason, intellect or the spirit over the somatic, is broken. The reading route that is traced allows us to observe that Somers

\footnotetext{
* El presente artículo se desprende mi tesis doctoral, titulada "Subjetividades marginales, cuerpo y escritura en la obra novelística de Armonía Somers", defendida en el año 2019 en la Universidad Nacional de Mar del Plata (Argentina) y desarrollada en el marco de una beca Doctoral del Consejo Nacional de Investigaciones Científicas y Técnicas, Conicet. ** Argentina. Doctora en Letras. Investigadora del Centro de Letras Hispanoamericanas (Ce.Le.His.), Becaria Posdoctoral del Consejo Nacional de Investigaciones Científicas y Técnicas, Conicet, Docente de la Universidad Nacional de Mar del Plata, Mar del Plata, Argentina. agustinaibanez@mdp.edu.ar
} 
Cuerpo, desnudez y silencio en La mujer desnuda de Armonía Somers | Ibañez

builds corporeality from silence, resignifying this no place that the body has had in the philosophical tradition. 


\section{Introducción}

Según se consigna en el Génesis, la pérdida del paraíso y el origen de todos los males son culpa de Eva. Esta mujer, creada por Dios de la costilla de Adán para su compañía (2:22), es la que ha cedido ante la tentación de la serpiente (Satán), quitándole a la carne y a los sexos el velo de gracia que los cubría. Subordinada al hombre por su origen y por el nombre "Varona" (2:25) que Adán le atribuye por haber sido tomada de él, la mujer es condenada y estigmatizada en el relato bíblico. No solo su cuerpo es una extensión de otro cuerpo, sino que es asociada con la debilidad, la provocación y el detrimento del varón en los placeres terrenales. Es Eva la mujer-símbolo quien inicia los atributos negativos cargados sobre la corporalidad femenina, pero también es ella la única que desafía las leyes impuestas, gesto revolucionario condenado por la doctrina católica.

La primera nouvelle de Armonía Somers, titulada La mujer desnuda (1950), propone - tal como lo advirtió Mailhe en relación a la versión homónima de 1966 - una inversión del mito de la caída original ${ }^{1}$. Somers retorna intertextualmente (Kristeva 3 ) al inicio del mundo narrado en el Génesis para, desde allí, reivindicar lo somático como parte constitutiva del ser humano y subvertir el contrato sexual y social que, al decir de Pateman, marca el poderío y los derechos de los hombres por sobre los de las mujeres y la accesibilidad y la posesión de sus cuerpos (10-11). A partir de este gesto, Somers deconstruye (Derrida, El tiempo de..., 23-27) la idea órfica y platónica del cuerpo como cárcel del alma, pero también su negación gnoseológica y su sumisión ante la Razón o el espíritu propugnadas por filosofías racionalistas e idealistas como las de Descartes o Hegel. Pues, y tal como se ahonda en el presente artículo, el cuerpo-desnudo y el cuerpo-decapitado de Rebeca Linke atentan simbólica y metafóricamente contra toda idea de organismo, de sistema y de unicidad, dando lugar a formas corpóreas que, por su alejamiento de lo normado, se presentan como monstruosas, perturbadoras o anárquicas.

1 En 1950, Somers publica en la revista Clima. Cuadernos de Arte su primera novela: La mujer desnuda. Un año después, en 1951, La mujer desnuda es publicada en forma de separata de la ya mencionada revista. En 1966 el texto vuelve a aparecer bajo el sello editorial Tauro con modificaciones de índole sintácticas, estructurales y argumentales. 
A pesar de la riqueza que posee el proyecto estético de Armonía Somers, son escasos los estudios que se han dedicado a su abordaje. Particularmente, la primera versión de La mujer desnuda (1950) se encuentra casi desértica de análisis. Hasta la fecha, los trabajos que existen ahondaron en las variaciones argumentales y sintácticas que presenta la versión de 1950 respecto de la de 1966; en las posibles relaciones entre la novela de Somers y la propuesta estético-cultural de la revista Clima. Cuadernos de arte; y, en el conflicto identitario que experimenta el personaje central del relato ${ }^{2}$. Es importante destacar también que muchas de las investigaciones que mencionan a La mujer desnuda insisten en resaltar el escándalo que provocó su irrupción en las letras uruguayas a mediados del siglo XX pero, a la hora de establecer el análisis de dicho texto, se dedican a explorar la segunda versión, la de 1966, que es por cierto la única que hasta la actualidad continúa reeditándose ${ }^{3}$.

La problematización del cuerpo decapitado y la desnudez femenina son dos de las tantas aristas que quedaron ávidas de análisis en La mujer desnuda de 1950. Estas temáticas han sido exploradas por la crítica en la versión de 1966. En dicho ejemplar, los críticos prestaron suma atención al pasaje de la (auto)decapitación de Rebeca Linke, suceso al que ubicaron en una zona liminal entre lo real, lo fantástico y/o lo imaginario en el sentido que le atribuyó Ángel Rama (1966); pero también, acontecimiento en el que advirtieron vasos comunicantes con el surrealismo y las imágenes creadas por Lautréamont en Los cantos de Maldoror (1868) ${ }^{4}$. Enfocados en la segunda versión de La mujer desnu$d a$, el cercenamiento que vivencia Rebeca Linke fue leído en relación al gótico, al terror y al expresionismo 5 . Y, además, como el acto por antonomasia que permite el ingreso en lo inconsciente, en la atemporalidad y en los instintos (Femenías, "Armonía Somers..." 11). En relación con esto último, se ha destacado la experiencia libre del deseo (Calafell

\footnotetext{
2 Véanse los trabajos de Franco (2013), Paolini (2019) e Ibañez (2014, 2016, 2019).

3 Vale señalar que recientemente, en diciembre de 2020, la editorial uruguaya independiente Criatura editora reeditó la primera versión de La mujer desnuda, la aparecida en 1950 en la revista Clima. Cuadernos de Arte.

4 Remito a Rodríguez-Villamil (1990); Olivera-Williams (1990); y, Alvarez Coba (2016).

5 López Abadia-Laya (2014) y Olmedo (2010) se han preocupado particularmente por estas cuestiones.
} 
Sala 206-213) y el desasimiento de la primacía de la Razón sobre lo somático (Lorio, "Plasticidad de..." 147). Otros aspectos que han sido estudiados en la versión de 1966 de La mujer desnuda en torno al cuerpo son: la desnudez, la intertextualidad con el relato bíblico del Génesis y la mitología griega, la subversión de los modelos de mujer y de feminidad imperantes en el Uruguay de 1950, la perturbación de la tradición cultural del patriarcado, el racionalismo y la identidad de género ${ }^{6}$.

La inexistencia de estudios que aborden el problema del cuerpo en la primera versión de La mujer desnuda justifica la necesidad de analizar el binomio cuerpo-desnudez en el ejemplar de 1950, tal como lo propone el presente artículo. El objetivo es demostrar que en la primera versión de la novela el cuerpo de Rebeca Linke se configura como un espacio desde el cual, por un lado, se cuestiona la relación de dominación de los hombres sobre las mujeres que propugna el relato bíblico del Génesis; y, por otro, se quiebra la supremacía que tanto la filosofía como la religión le han otorgado a la Razón, al intelecto o al espíritu por sobre lo somático. Para dar cuenta de lo expuesto, en un primer momento, se analiza el lugar de sumisión que los cuerpos-femeninos poseen ante los cuerpos-masculinos tanto en el acto sexual como en la vivencia de la sexualidad, para luego examinar el alcance del cuerpofemenino-desnudo de Rebeca como espacio de resistencia frente a la autoridad y el dominio que el cuerpo-vestido y el cuerpo-masculino poseen dentro de la sociedad representada. En segundo lugar, se analiza la nueva organización corporal que Rebeca Linke ejecuta como el gesto simbólico que le permite la anulación de la Razón pero, sobre todo, la posesión y la afirmación del cuerpo como lugar desde el cual conocer y relacionarse con el mundo y con los otros.

El recorrido de lectura trazado permitirá observar que en $\mathrm{La} \mathrm{mu-}$ jer desnuda de 1950, Somers resignifica ese sin-lugar que ha tenido lo corpóreo a lo largo de la tradición filosófica y religiosa. Pues, lejos de revestirlo de la negatividad que implica lo no-dicho, el cuerpo es construido desde el silencio, detrás de la palabra escrita para, desde allí, tornarse aún más existente. $\mathrm{O}$ bien, para dar cuenta de que el lenguaje

6 En particular, remito a los trabajos de: Mailhe (1997), Femenías (2002), Calafell Sala (2010), Dalmagro (2012), Olivera-Williams (2011), La Rocca (2013) y, Montoro Martínez (2005). 
- dominado por una lógica binaria - se encuentra viciado, contaminado, para poder decir aquellas cosas que reiteradamente ha expulsado de su alcance. De ahí que hacer hablar al cuerpo desde el silencio se transforme, en esta novela de Somers, en una forma de restituirle su lugar en el mundo. En efecto, y si en el Génesis fue el Verbo, el logos, el principio que desterró la carne del hombre, entonces ¿cómo hablar con él o desde él sobre el cuerpo sin seguir expulsándolo? ¿Cómo fundar una nueva historia que retorne la corporalidad al hombre haciendo uso de un lenguaje en el que nunca tuvo lugar? En Somers, la respuesta pareciera ser: con y desde la elipsis, desde el margen, desde los bordes de la palabra.

\section{Cuerpos que (no) importan}

Dentro del pueblo patriarcal y heteronormativo (Warner 8) de $\mathrm{La} \mathrm{mu-}$ jer desnuda (1950), el cuerpo-femenino es ubicado en un lugar de marginalidad y opresión frente al cuerpo-masculino. Reducido a un mero instrumento de satisfacción sexual, es violentado y usado como espacio de inscripción y legitimación del discurso que distingue y funda las distancias entre aquellos que poseen, gozan y dominan su propio cuerpo de aquellos que no. Tal es así que, en la oscuridad de la noche, los hombres buscan a las mujeres con las que cohabitan para cancelar de manera brutal sus impulsos sexuales:

Entonces el hombre comenzó a manejarla brutalmente, le hizo tomar la posición, como a un pobre animal cansado que ya no tiene voluntad ni fuerza...

Abre esas piernas, ábrelas o te las corto con el hacha. Ya, ya, déjame hacer yo no soporto esto - dijo el hombre con un torcimiento de angustia, apoderándose del enflaquecido cuerpo...

el hombre la atenaceó aún más fuertemente. La hendía a golpes de sexo, como si estuviera esgrimiendo el hacha contra un árbol. (Somers 83) ${ }^{7}$

Lejos de ser un cuerpo-deseante, la anatomía femenina emerge como objeto de deseo de otro al que teme fallar y debe complacer. Se

$7 \quad$ A partir de este momento, todas las citas de La mujer desnuda de Armonía Somers corresponden a la primera versión del texto, la de 1950 aparecida en Clima. Cuadernos de Arte. 
configura, así, como el cuerpo-dócil, el cuerpo-manipulable, el cuerpo-sometido. No solo responde a los imperativos del hombre ("Abre", "ábrelas", "déjame hacer"), sino que es arrojado espacialmente a un lugar semejante a lo inerte: "le hizo tomar la posición, como a un pobre animal cansado que ya no tiene voluntad ni fuerza" (Somers 83). La comparación utilizada para describir la manipulación corporal exhibe la obediencia y la imposibilidad de acción de los cuerpos-femeninos ante los cuerpos de sexo opuesto, pero también su expulsión de lo humano: no son los que gozan, sino los gozados; no son los dotados de albedrío e intelecto sino lo animal. Esta zona de exclusión o de abyección (Butler, Cuerpos que importan... 19-20) los objetualiza inscribiéndolos como una cosa necesaria que delimita y fortalece el poderío del cuerpo-masculino. Pues es en la medida en que el cuerpo-femenino habita la zona de lo invivible que la corporalidad masculina se (auto) configura en el lugar del soberano, del sujeto que desea y dictamina la norma. De ahí que en los roles que ocupan los sexos en la ejecución del acto sexual sea el cuerpo-femenino el penetrado, el violentado y el pasivo frente al cuerpo-masculino entendido como activo y penetrador. Aspectos, todos ellos, que se sintetizan en la fuerza de la oración disyuntiva "Abre esas piernas, ábrelas o te las corto con el hacha" (Somers 83) y que, bajo una profunda violencia, exhibe las únicas opciones que la mujer posee en el mundo representado: la obediencia o la muerte. Dentro de esta lógica binaria y opresora, la mujer no es más que un bien de consumo yacente, inmóvil y desechado luego de proveer el beneficio pretendido.

Estas relaciones de poder entre los cuerpos encuentran su origen en el discurso bíblico. Según el relato del Génesis que el sacerdote del pueblo somersiano reitera en sus homilías, la mujer fue creada por Dios después de Adán para su compañía: "Estando el primer hombre dormido, Dios aprovechó el propio hueso de aquella carne del hombre para formar una mujer. Y colocó a la mujer delante del hombre para que la hallase al despertar del sueño" (Somers 10; cursivas en el original). La mujer se presenta, así, como un regalo de Dios para el hombre al que, por mandato celestial, debe obedecer y satisfacer. No solo es la criatura de Dios, sino que su cuerpo es carne de otra carne. Su organismo deviene, desde y por el mito, impropio en tanto deriva de un fragmento humano de otro sexo. De ahí su desposesión y su lugar opresivo frente al cuerpo-masculino. Su carne no es suya y, por lo tanto, puede 
ser apropiada por otro, o bien, tomada por aquel del cual se origina. En tanto cuerpo usurpado, parásito, injerto de otro al que repite, refleja y adeuda su propia existencia, su violación no se comprende como falta:

— ¡Desnúdate, mujer, apaga la luz y desnúdate. Vamos, pronto!...

- Sí, toda desnuda, pero que yo no te vea ¿sabes? que no te vea. Y pronto, ya, pronto si no quieres que te derribe para hacerlo...

... Le exigen que desnude todo eso sin mostrarlo y que se tienda luego como una odalisca en aquel lecho ... para forzarla después quién sabe a qué vergüenzas, y sin derecho al rubor ni a la protesta.

(Somers 94)

El fragmento citado permite entrever los códigos que enmarcan las relaciones sexuales dentro de la vida conyugal. Uno de ellos es la oscuridad, atmósfera por excelencia que sirve para liberar los deseos más recónditos, pero sobre todo que transforma el cuerpo ajeno en lo desconocido y lo invisible. Otro de los códigos es la entrega de la mujer ante el hombre cual esclava sexual, sin tener posibilidad de decidir las acciones practicadas sobre su cuerpo. A lo que se añade, además, la anulación de su voz dando cuenta de que el poder de los hombres sobre el cuerpo-femenino no está dado únicamente por su órgano sexual o por la aplicación de la fuerza, sino por la palabra. Ella es el falo que invisibiliza, que excluye y exige: “¡Desnúdate!” "Ya” “¡Pronto!” (Somers 94). Es la palabra-falo la que pervierte y objetualiza el cuerpo de la mujer. Si para Simone de Beauvoir (2011) y para Pierre Bourdieu (2000) la penetración en tanto práctica sexual regida por los principios activo/pasivo constituía una manifestación de dominación sobre un otro, podría pensarse que en Somers es la palabra, también, en tanto símbolo fálico, la que penetra y marca la posesión y la apropiación de los cuerpos. Es el logos, el verbo, el que excluye y somete . $^{8}$

No obstante, y más allá de la relación de dominación/subordinación que exhibe el acto sexual brutal que acontece en el pasaje aludido, se

8 Para este planteo, se toma en cuenta el carácter heteronormativo y patriarcal que Luce Irigaray (2007) le atribuye a la lengua en Yo, tú, nosotras y que, de acuerdo con su propuesta, niega, invisibiliza y anula la diferencia sexual existente entre hombres y mujeres. 
advierte que lo impronunciable es el cuerpo. Ni la anatomía femenina ni la masculina tienen lugar dentro de la narración de la escena. Se sobreentienden, pero no se explicitan. Pues es tal la represión y la prohibición en torno a la carne que no puede hablarse de ella más que de modo indirecto. Nótese, por cierto, que la desnudez del cuerpo femenino no solo es excluida de la mirada del varón, quien exige su ocultamiento en la oscuridad, sino que es expulsada, también, del discurso. Tal es así, que el cuerpo-femenino-desnudo es (re)presentado por la voz narradora como: "todo eso" (Somers 94). El enlace de ambos pronombres muestra la imprecisión de la corporalidad al tiempo que la cosifica, la desprecia y, debido a la inexistencia de un antecedente que explicite su referencia, la exilia del logos. En otras palabras, el cuerpo aparece como lo inenarrable o elidido por el lenguaje pero que, y debido a ser lo silenciado, adquiere fuerza y poder.

Ahora bien, la subyugación y la negación que poseen los cuerposfemeninos dentro del pueblo de La mujer desnuda (1950) son puestos en pugna por el personaje central del relato: Rebeca Linke. En contraposición a las féminas violentadas, usurpadas y desnudadas contra su voluntad por los hombres, Rebeca se desnuda a sí misma, condición que tanto en su alcance literal como metafórico la libera de las prácticas socioculturales, religiosas y políticas que rigen el mundo representado. En tanto mujer, su organismo no solo es lo otro o la diferencia absoluta, sino que es un espacio insurrecto que desafía el mundo patriarcal y el castigo enviado por Dios ante la desobediencia de Adán y Eva. Tal es así que Rebeca, a diferencia de las otras féminas del relato, nombra y disfruta de su propio cuerpo-desnudo, descubre su anatomía y la posibilidad de darse placer a sí misma: “Luego bajó las manos, se acarició a sí misma, de flanco. A medida que caminaba, iba sintiendo el mecanismo del hueso oculto ... Cuando la caricia le llegó hasta el pecho, tuvo un sacudimiento. Sus senos pendían tiernos ... Los levantó con un gesto de abundancia" (Somers 79-80). El cuerpo de Rebeca ya no es el cuerpo-pasivo ni el cuerpo-gozado o silenciado, sino que es un cuerpo que se goza a sí mismo porque se sabe propio, cuerpo-erógeno, deseante, hablante. Pues, a diferencia de las otras mujeres del pueblo, ya no responde a la imagen de mujer-odalisca ni a la mujer-penetrada, sino que es ella la que actúa, la que busca, la que incita al placer, invirtiendo así los roles que poseen los cuerpos-masculinos y los cuerposfemeninos en el acto sexual: 
-Ven, toca, estoy desnuda...

La voz secreta de la mujer era cálida ... El hombre la sentía sobre su oreja al tiempo de oírla. Y de esa doble sensación brotaba lo otro, tan fabulosamente dulce y extraño que le metían en el cuerpo. (Somers 82)

Frente a esta mujer que toma el lugar de dominación en el acto sexual, el hombre responde desde la sumisión hasta devenir cuerpopenetrado.

Sin embargo, y más allá del lugar de poder que toma el cuerpo de Rebeca Linke en lo que atañe a los comportamientos sexuales, su anatomía sigue permaneciendo, al igual que en los relatos bíblicos y en la tradición filosófica, en lo no-dicho. La desnudez, en tanto mostración del cuerpo, constituye la gran ausencia de la novela de Somers. Más allá de aparecer nombrada, la carne no es descripta ni mucho menos visible para los personajes del texto somersiano. Al igual que el lugar elíptico que posee en el Génesis, opera y adquiere espesor desde el silencio, desplazándose metonímicamente como el deseo. El cuerpodesnudo de Rebeca funciona así como un significante puro sin significado preexistente que, por esa falta y por ser huidizo, se torna cada vez más indestructible (Lacan, Seminario III... 263-265).

El espacio vacío que abre lo no-dicho fomenta que la desnudez se sobrecargue de múltiples contenidos por parte de los habitantes del pueblo que encuentran en ese cuerpo-desnudo que no pueden observar ni poseer, la materialización de sus fantasías eróticas, sexuales, amorosas, infantiles. Para los niños del pueblo, por ejemplo, la mujerdesnuda se asocia con esas imágenes estereotipadas de mujer transmitidas en cuentos y canciones: mujer-sirena, esposa, ama de casa. Para los adultos, en cambio, posee un "largo y negro pelo suelto y los brazos caídos" (Somers 88). Imagen, esta última, que resalta la excitación que provoca el cabello femenino y su asociación con la rebeldía, los instintos, el pecado y el mal. Pues, el desnudo de Rebeca es imaginado como striptease. De ahí que sea entendido por ellos como un "delito" (Somers 75), un desvío y una infracción de la ley divina. En tanto acto revolucionario, debe ser aniquilado porque les recuerda "lo que ellos se cubrían, cuerpo y alma. La vergüenza de sus pobres vidas ... Aquella criatura desvestida, ... les había traído el terror de sus desnudas almas" (Somers 122). En otras palabras, los obliga a retornar a 
la libertad primigenia: la desnudez corporal prohibida por el discurso del catolicismo. Pero, sobre todo, y apelando a los sentidos que abre el uso del término "criatura/creatura", los interpela a devenir individuos ilegales dentro de los mandatos de Dios que rigen la aldea. Pues Rebeca no solo es la creada o la criada por Dios sino el ser que, debido a su desobediencia, se transforma en lo monstruoso que contagia a otros. Es el espejo que refleja y devuelve el despojo, el pecado y la falta de todos los que la observan.

Por el temor de perder el lugar que ellos ocupan dentro del mundo representado, los hombres de La mujer desnuda (1950) buscan repetir con Rebeca Linke la posesión del cuerpo de Eva que hizo Adán. Lejos de advertir en su liberación un gesto propiciatorio para generar su propia autonomía, quieren tomarla para refundar su poderío y retornar al vestido y a los códigos sociales que regulan los cuerpos y garantizan su hegemonía. Enceguecidos por el relato del Génesis, reinstalan la pregunta por la posesión: “¿De quién era la mujer, al fin? ¿De todos, de nadie, de todos y ninguno? ¿Quién debería entregarla, reivindicarla y hasta ajusticiarla si era preciso, para calmar el odio ingobernable que ella les producía?" (Somers 121). Si desde el mandato divino la mujer es propiedad del hombre, ¿quién de todos ellos es el dueño de esa nueva fémina capaz de desafiar, con la pérdida de pudor y vergüenza ante su propia corporalidad, el lugar de poder que en tanto hombres les correspondía? ¿De quién, acaso, es aquella mujer capaz de mostrarles su propia desnudez y rebelarse ante Dios? ¿Quién es el Adán de la Eva somersiana?

Una vez más, el discurso religioso les ofrece la respuesta: el cuerpofemenino-desnudo de Rebeca Linke es, al igual que la Eva bíblica, de "propiedad colectiva" (Somers 121). Tal es así que, ante la imposibilidad de poder tomar su cuerpo de modo análogo como con sus cónyuges, inician su persecución, su asesinato y hasta verbalizan la opción de una violación colectiva. Amparados en el derecho que el discurso heteronormativo de la Biblia les adjudica sobre la mujer, organizan una feroz expedición que rememora las cazas de brujas promovidas por la Iglesia y la justicia civil durante la Edad Media en pos de sostener el orden social establecido.

De cada puerta salían otros hombres ... viendo a los demás armados corrían ellos también al interior, traían la azada, la pala, los ras- 
trillos, cualquier cosa, y se las colocaban en el hombro, mientras corrían a las otras puertas, gritando, golpeando fuerte, empujando hacia adentro a las mujeres y a los niños. Algo les advertía que eran soldados de una guerra de hombres solamente. Algunos trataron hasta de salir pertrechados con su sexo, recordando que lo tenían, por lo menos. ¿No era una mujer desnuda el enemigo? Pronto quedó integrado el ejército bárbaro. (Somers 90)

Lo que no soportan es la libertad que implica la aniquilación de las instituciones disciplinarias (Foucault 140-146) de la sociedad y de los cuerpos: la Iglesia, el matrimonio, el falogocentrismo (Derrida, "El cartero..." 351-355). De ahí que a los instrumentos fálicos (pala, rastrillos) para provocar el exterminio de Rebeca, se sume "salir pertrechados con su sexo". Es la portación del falo, en tanto símbolo de privilegio y lugar de poderío, lo que hay que salir a defender porque su pérdida implica la invisibilización, la otredad absoluta, la anulación de la diferencia entre los sexos, el sometimiento de la mujer a sus deseos. Hay que exhibir el falo, remarcar que ellos son los que lo tienen, para recordarle a ese cuerpo-mujer que es ella la castrada y el objeto de deseo. Su propagación no solo trae el peligro del contagio de su libertad hacia otras féminas, sino que los ubica en el lugar de los doblemente mutilados: han perdido el valor que implica la portación del falo-órgano sexual y ya no son los deseados.

\section{Rebeca Linke: decapitación y fragmentación corporal}

Asociada a lo siniestro, lo fantástico y lo macabro, la decapitación como forma de muerte recorre la historia del ser humano, los relatos míticos, la pintura y la literatura. Basta aludir, por cierto, a las ejecuciones manuales llevadas a cabo por medio de hachas o espadas durante la antigüedad hasta el uso de máquinas como la guillotina para eliminar en espectáculos públicos a los condenados a muerte. O bien, y ya dentro de la mitología griega, recordar a Perseo, héroe que decapitó a Medusa; o a Orfeo cuya cabeza, según narra el poeta Ovidio, fue tirada al río por las Bacantes luego de ser desmembrado. En el marco de los relatos bíblicos, podría evocarse a Judith, mujer hebrea que cercena la cabeza del general asirio Holofernes; o a Juan el Bautista, hombre decapitado por Herodes a pedido de Salomé. E incluso, en los relatos de los pueblos originarios de América, aludir a Hun Hunahpu, dios de 
la fertilidad cuya cabeza creció en un árbol de jícaras tal como consta en el Popol Vuh. O, bien, remitir a las obras pictóricas de Caravaggio o a las producciones literarias de los hermanos Grimm, Washington Irving, Lewis Carroll o Lovecraft.

Fuera de los múltiples escenarios en los que se han producido decapitaciones a lo largo del tiempo, la revisión de esta práctica conduce a asociarla con el castigo y la herida de la alteridad sobre el propio cuerpo. Tanto en su aspecto imaginario como real, la separación de la cabeza del tronco se presenta como un espectáculo que zigzaguea entre la atracción y la repulsión. Por un lado, capta la mirada del observador por lo espeluznante que es en sí misma la fragmentación corporal y la posibilidad de pensar un cuerpo sin cabeza, órgano que dirige al tronco y en el que habita la razón, el habla y la emoción. Por otro lado, genera aversión por visibilizar la imposición de una norma y las consecuencias que pueden padecerse ante su desvío. Instancia, esta última, que configura la decapitación como un acto que busca inscribir en el propio cuerpo el poder de la alteridad y que, desde una mirada foucaultiana, pretende fabricar y reproducir cuerpos e individuos sometidos y dóciles.

En la primera versión de La mujer desnuda (1950), el cuerpo-desnudo de Rebeca Linke, ya sea en su alcance alegórico como material, es producto de un acontecimiento anterior: su (auto)decapitación, suceso que tiene lugar dentro de la casa de campo a la que se traslada el día de su trigésimo natalicio. A diferencia de las decapitaciones aludidas al comienzo de este apartado, el descabezamiento ejecutado por Rebeca se caracteriza por ser un acto que ella emprende sobre sí misma. Este aspecto la ubica en una zona de poder sobre su propio organismo, pues es quien ejecuta y quien padece, al mismo tiempo, el desmembramiento:

antes de caer abatida por sus últimas palabras, pudo aún recordar algunas de aquellas pequeñas cosas; por ejemplo, que dentro de su libro ... había una pequeña daga toledana que era una obra de arte, tanto como para decapitar a una mujer enloquecida ... La mano está muerta, el dedo no puede, no alcanza ... Es entonces cuando la daga va a demostrar que ella sí lo puede. Sabe hacer de por sí lo que otras no saben ... Y es así como se desplaza, atraída por las puntas de aquellos dedos, hacia la mano. Es claro que es hacia una mano 
que está adherida a un brazo, que pertenece a su vez a un cuerpo, un cuerpo con cabeza, con cuello. Una cabeza, algo tan importante, sobre eso tan vulnerable que es un cuello.

El filo penetró sin esfuerzo, a pesar del brazo muerto, de la mano sin dedos. Tropezó con innumerables cosas - venas, cartílago, huesos articulados, sangre viscosa y caliente- con todo menos con el dolor, que entonces ya no existía.

La cabeza rodó pesadamente, como un fruto. Rebeca Linke vió [sic] caer aquello sin alegría ni pena. (Somers 76$)^{9}$

Más allá de la animización de la daga, objeto punzante que produce el corte, es la mano de Rebeca la que lo dirige, dando lugar a un estado corporal y subjetivo diferente. Lejos de provocar el deceso, la decapitación pareciera ser una posibilidad de vida, "un acto ritual de muerte y renacimiento, por el cual el sujeto se constituye voluntariamente a sí mismo como otro" (Mailhe 90) ${ }^{10}$. No solo se ejecuta sobre un cuerpo ya inerte, nótese la insistencia en resaltar el desfallecimiento de las extremidades encargadas de la manipulación física ("la mano está muerta", "el brazo muerto", "el dedo no puede, no alcanza", “mano sin dedos"), sino el pasaje de un estado de languidez a uno de vigilia a partir de la separación de cabeza y tronco. En efecto, fuera de marcar la pérdida o la anulación del sentido de la visión, facultad que recae en los órganos ubicados en la parte superior del cuerpo humano como lo son los ojos y el cerebro, la división corpórea separa la materia sensible del alma o el espíritu: "La cabeza rodó pesadamente como un fruto. Rebeca Linke vió [sic] caer aquello sin alegría ni pena" (Somers 76). Tal como lo advirtió Montoro Martínez respecto de la versión de 1966, la cabeza de Rebeca rueda por el piso como la de Holofernes (223).

No obstante, y a diferencia de la Judith bíblica, Rebeca no es quien decapita a otro sino a sí misma. Es ella quien, desde un afuera corpo-

9 En la versión de 1966 de La mujer desnuda, el fragmento citado es transformado en una única y extensa oración con una estructura sintáctica compleja. Además, se eliminan los detalles que trazan el carácter acabado del objeto ejecutor del desmembramiento y los signos de puntuación. A su vez, las siguientes construcciones presentes en la versión de 1950: "pudo aún recordar" (Somers 76) y "mujer enloquecida" (Somers 76) cambian, en la reescritura de 1966, por: "logró evocar" y "mujer prisionera", respectivamente.

10 El artículo citado de Mailhe (1997) se dedica al análisis de la segunda versión de $L a$ mujer desnuda, la de 1966. 
ral, se observa desarticulada transformándose en espectadora de la decapitación de su propio cuerpo como si se tratara de una especie de duplicación o desdoblamiento subjetivo y corporal. Pareciera, de algún modo, que el ser de Rebeca Linke es ajeno, extraño y externo a la materia sensible. Su existencia expulsa al cuerpo. Pues, y tal como se infiere del fragmento citado, las percepciones visuales perduran más allá de la aniquilación de la irrigación sanguínea entre torso y cabeza, de modo tal que la facultad de observación del individuo se ubica en algo que excede los órganos encargados de este sentido. Rebeca Linke contempla su cuerpo y su cabeza amputada desde un exterior difuso, aproximándose al dualismo ontológico alma/cuerpo propugnado por Platón, ya que sigue existiendo por fuera de la materia sensible a modo de entidad incorpórea. ¿ $\mathrm{Si}$ no es desde el exterior de su cuerpo, entonces, desde dónde se observa a sí misma Rebeca? ¿Cómo habitar, si no es desde afuera, un cuerpo que no le pertenece, que es de otros antes que de sí misma? ¿Cómo morar un organismo que la expulsa porque no se adecua a las normas imperantes? ¿Cómo hacerse de un cuerpo que ya desde antes de la escisión se sabía fragmentado, impropio, extraño? Vale señalar que la separación cabeza/cuerpo está precedida de una atomización corporal previa, como si se tratara de un organismo sin coordinación o enlace interno. Nótese, al respecto, la presencia inconexa de partes disímiles del cuerpo en el pasaje citado con anterioridad: manos, dedos, cabeza, cuello, cartílagos, huesos, sangre. Incluso, y si se tienen en cuenta los órganos aludidos, se advierte no solo una preponderancia de la parte superior del tronco humano sino una invisibilización de aquellas zonas que no se mencionan configurando, antes de que acontezca su (auto)decapitación, un cuerpo incompleto. Situación que, luego de la escisión de su cabeza, se invertirá producto de la (re)organización corporal que esta habilita y que implicará desde la germinación de una nueva cabeza hasta el descubrimiento de zonas erógenas, el autoerotismo y la alusión a nuevas partes corporales (senos, palmas, axilas, cabellos, piernas, boca, cintura, caderas, vellos). En suma, la (auto)decapitación provocará que Rebeca surja en su "primera noche poseída" (Somers 79): se tenga a sí misma, se libere de los imperativos que controlan su carne, se sepa dueña de su cuerpo, de sus deseos y de su destino.

Por lo expuesto, podría afirmarse que la (auto)decapitación de Rebeca Linke se aleja de la connotación de muerte y punición que poseía 
este acto en los relatos míticos, literarios y pictóricos aludidos al inicio de este apartado. Más bien, y en un sentido metafórico, se levanta como una reivindicación de lo somático frente a la Razón, el alma o el espíritu. Al eliminar su cabeza - lugar en el que reside el alma y la parte divina del hombre (Platón 187) y que simbólicamente alude a la Razón-, Rebeca inscribe en su corporalidad la liberación de todo aquello que daba lugar a su división subjetiva. Recuérdese la duplicidad interna y externa que, antes cercenarse, la protagonista presentaba como operatoria para sobrevivir a los mandatos del mundo patriarcal representado:

Rebeca Linke era una mujer sobrellevando a la otra, a la de afuera, le cumplió ... todas las obligaciones ... Cepillarse el cabello (la mujer que vivía por fuera tenía el cabello largo y negro), cepillarse los dientes, bañarse toda entera. Ya estaba el cuerpo exento (la mujer de la Linke era delgada y grácil, por lo cual no le sentaba bien su cabeza pensadora). (Somers 74$)^{11}$

Envuelta en este contexto de duplicidad yoica (un ser-para-sí-misma presidido por la libertad y un ser-para-los-demás que persigue la satisfacción de las imposiciones externas), la escena de decapitación del texto de 1950 se entiende como un acto que aspira a la autonomía. Es decir: una liberación de aquellas puniciones socioculturales que le impiden poseer una unicidad y dejar de vivir en una franja que oscila entre ser y parecer.

En tanto zona de residencia del alma - y dada la fuerte intertextualidad religiosa que signa la novela-, se observa que el exterminio de la cabeza aleja a Rebeca del catolicismo y de la adoración de una vida espiritual por encima de una existencia terrenal. Es decir, conecta al individuo, en este caso a la mujer, con su propia materialidad: el cuerpo, componente que la religión ha relegado, cubierto con ropajes y señalado como pecaminoso e incitador de la lujuria y el placer desmedido.

11 El fragmento citado, perteneciente a la versión de 1950, fue eliminado en su totalidad en el ejemplar de 1966. Dicha anulación diluye, en la reescritura de la novela, la contradicción interna del personaje. Ya no hay en ella una pugna entre un "deber ser" y un inconsciente/deseo/impulsos, sino una consolidación y asunción de su otredad, lugar al que la mujer es arrojada por el pensamiento binario-jerárquico de la modernidad. Esto fortalece su posicionamiento y acentúa su enfrentamiento contra los valores de la sociedad representada. 
Asimismo, y si se tiene en cuenta desde el psicoanálisis la asociación que se ha realizado de la cabeza con el pene y con la castración, puede pensarse la (auto)decapitación de Rebeca como metáfora de aniquilación del poder fálico que impera en el pueblo representado y al que luego ella, con su cuerpo desnudo, desafiará ${ }^{12}$. Recuérdese, tal como lo advierte Irigaray, que la ausencia de pene en la mujer fue entendida como un atributo negativo que condujo a justificar su sumisión frente al hombre (Espéculo... 40-43). En este sentido, pensar la amputación de Rebeca como una expulsión de su cuerpo de todo aquello que posee una carga masculina, permite aproximar su desmembramiento a un acto de resistencia y lucha femeninas. Pues al aniquilar su cabeza se (re)inscribe y afirma como lo que es: una mujer sin-pene, en donde la negación no posee carga negativa, sino que anticipa el enfrentamiento ante el mundo heteronormativo, religioso y falocrático en el que habita. Nótese, por ejemplo, la parodia que su decapitación hace de la construcción social de la mujer como un sujeto que fácilmente "pierde la cabeza". Fuera del sentido metafórico de esta expresión popular asociada a la falta de raciocinio, o bien, a la histeria o locura femenina, en La mujer desnuda (1950) Rebeca materializa la amputación de dicho órgano llevando al absurdo y a una imagen surrealista su propia construcción corporal.

Ahora bien, tal como se anticipó, la nueva distribución corporal que acontece a partir de la división entre cabeza/torso ejecutada por Rebeca propicia una relación diferente con su nuevo cuerpo:

La mujer colocó la cabeza sobre una mesilla baja, dio unos pasos atrás, buscó el efecto en la penumbra ... La mujer permaneció unos minutos contemplando el cambio. Quizás le enamorase mucho más esta que la vaquera. Era menos ingenua, más guerrera, más brava ... Se arrodilló, quedó a la altura de la otra. "Amada, quiero besarte", logró decirle sordamente mientras se le aproximaba. Pero no pudo lograr el acto (Somers 78)

Rebeca no solo se observa a sí misma desde un exterior, sino que este mirarse fragmentada lejos de provocarle espanto la atrae hasta

12 La connotación sexual que ha tenido la decapitación, producto de la asociación simbólica entre cabeza/pene, ha sido marcada por Freud en su interpretación del mito de Medusa. 
querer besar ese órgano que se arrancó. Apelando a los aportes desarrollados por el psicoanálisis, podría decirse que la escena se abigarra de un profundo autoerotismo y narcicismo, entendiendo por ello la carga libidinal sobre la propia imagen. En efecto, su cabeza cercenada deviene espejo en el que ella se mira fascinada a sí misma, no habiendo más lugar que para una relación entre ese yo-externo y ese fragmento de su cuerpo al que configura como su primer amor ${ }^{13}$. Esta relación autoerótica es lo que habilitará, desde una concepción freudiana y lacaniana, el tránsito de un cuerpo fragmentado a una integración de su experiencia corporal, el pasaje de ser un cuerpo a tener un cuerpo $^{14}$. Pues, y tal como lo advierte Lacan, el cuerpo se tiene en la medida que hay una experiencia con el lenguaje ("El estadio" 86-93). Y es a medida que Rebeca interactúa con los órganos y las partes que ella misma despedaza de su organismo, que va apropiándose y reconstruyendo una corporalidad que, antes de su (auto)decapitación, no tenía. Esta (auto) estimulación dará comienzo a la relación de Rebeca Linke con otros individuos y con el mundo. Pero, sobre todo, posibilitará la posesión de su cuerpo gracias a una nueva organización corporal:

Con ligera y eficaz maniobra, la mujer tomó la cabeza de la mesilla, se la colocó a sí misma de un golpe duro ... se quedó tambaleando a causa de ese peso ya olvidado. Era, además, terriblemente extraño volver a mirar el mundo por aquellos ojos ... Todo rehecho ... ya estaba ella coronada de nuevo por su completa vigilia, coronada y sin amor posible, aunque esa vez exenta de pensamiento y de violencia ... Su anémica cabeza, aunque reintegrada, ya no era la misma. Pero ella, la mujer, tenía entonces su desnudo en cambio ... Se sentía sin peso, livianamente liberada de algo (Somers 78)

Podría pensarse, aludiendo a Deleuze y a Guattari, que es a partir de la ruptura de la estructura de su organismo que su cuerpo devie-

13 Se utiliza la noción de espejo en el sentido que Lacan le atribuye a la hora de pensar en el estadio del espejo: fase en la que el niño, en pleno desarrollo de su psiquismo, percibe por primera vez su imago corporal como un todo completo y orgánico gracias a la identificación y el reconocimiento en el Otro ("El estadio", 86-93).

14 Tanto para Freud como para Lacan, el ser humano en sus primeros meses de vida se siente fragmentado. Según Freud, es a partir de la relación con su madre y de la erotización de su cuerpo que comienza a tener registro de sus límites corporales hasta constituirse como una unidad autónoma e independiente de la madre. Lacan, por su parte, señala que es el estadio del espejo el que le permite al niño pasar de una imagen fragmentada a una totalidad o integración corporal. 
ne un "cuerpo sin órganos" (156). Su antigua cabeza pensante aparece ahora "exenta de pensamiento y violencia", liviana, diferente; sus ojos resultan extraños; su cuerpo vestido adopta la desnudez y la exposición de la carne. Rebeca Linke se enfrenta a la organización de los otros cuerpos que habitan el pueblo: llámese el cuerpo de la Iglesia, el cuerpo del patriarcado, de la heteronorma, de la familia, de la organización social. Arrancada su cabeza, Rebeca experimenta una corporeidad móvil, etérea y fluctuante. Un cuerpo que, al igual que Dios, es omnipresente, imperceptible y todopoderoso. No obstante, y en contraposición a la figura divina cuya potestad está ligada al castigo que genera la desobediencia de sus mandatos, el poder del cuerpo de Rebeca recae en su plena libertad. Esto es: la desorganización y la distancia que presenta respecto de las normas religiosas y morales que dictaminan aquello que pueden y deben hacer los cuerpos. Incluso, su soberanía se recarga aún más a partir del conjunto de enunciados, ideas y percepciones que los otros elucubran sobre ella, transformándose así en cuerpo erotizado, insurrecto, rebelde, anárquico, desnudo, ardiente, fantástico, pecaminoso, irreal. Su cuerpo no es la sumatoria de órganos ni mucho menos un croquis anatómico, sino la mezcla de los discursos que emiten los individuos del pueblo sobre él, dando cuenta del carácter performativo que poseen, en términos de Butler, las estructuras corporales $^{15}$.

\section{Coda}

En La mujer desnuda (1950), Armonía Somers materializa una recuperación del cuerpo de la mujer. Dicho retorno a lo somático implica un volver a escribir el relato de origen de esta desposesión: la historia de la creación del hombre narrada en el Génesis. Pero también la anulación de la Razón y del intelecto, facultades que a lo largo de la historia han sido privilegiadas por sobre la carne, los instintos y lo sensorial.

El organismo desnudo y decapitado de Rebeca Linke, la Eva-somersiana, adviene voz que (ex)pone, en su alcance de situar en un afuera,

15 Tanto en El género en disputa (2007) como en Cuerpos que importan. Sobre los límites materiales y discursivos del "sexo" (2002), Butler propone que el género y los cuerpos se construyen a partir de prácticas discursivas reiteradas que circunscriben, normativizan y controlan a los sujetos. Son instancias performativas: prácticas constantes que siempre implican a otro que ejerce poder. 
la hipocresía, las injusticias y las opresiones que impiden que el hombre asuma su humanidad, su carnalidad y su sexualidad. Para ello, se (auto)construye dejando de ser la extensión de un fragmento corporal del hombre. No es él quien da corporalidad a la mujer, sino que es ella misma quien se reivindica como individuo corporal, sensorial y carnal que, además, brinda a otros la posibilidad de liberarse y de (auto)descubrir también su organismo.

Reconquistar el cuerpo que le ha sido constantemente negado a la mujer implica en Somers no solo inscribirlo como espacio de lucha, crítica y resistencia contra todo discurso dominante y coercitivo de la autonomía del individuo y su poder de acción, sino sobre todo buscar el modo de hacerlo presente y existente. ¿Cómo hablar de aquello que se ha silenciado sino desde una apropiación del lugar que se le ha impuesto? ¿Cómo hacer oír y representar lo que para el logocentrismo (Derrida, De la gramatología 7-10) no ha sido más que irrepresentable, innombrable y lo otro sin armar un propio lenguaje? Armonía Somers encuentra el modo de hacer audible al cuerpo desde esa zona en la que siempre ha estado condenado a habitar: el margen, el borde, la elipsis. De ahí que la desnudez, entendiendo por ello la mostración de los órganos y la piel, no se pronuncie ni explicite hasta sobrevolar en el discurso y tornarse omnipresente por ser lo impronunciable o lo inenarrable con la palabra.

Lo subversivo, entonces, en La mujer desnuda no es hablar del cuerpo y la desnudez, sino hacerlo presente desde la ausencia. Cuestionar los principios y valores morales y religiosos sobre los que descansan las sociedades representadas desde un lenguaje que emerge para bordear, para decir y no-decir, al mismo tiempo, aquello condenado a callar.

\section{Referencias bibliográficas}

Butler, Judith. Cuerpos que importan. Sobre los límites materiales y discursivos del "sexo". Buenos Aires, Paidós, 2002. Impreso.

Calafell Sala, Nuria. La convulsión orgiástica del orden: Sujeto, cuerpo y escritura en Alejandra Pizarnik y Armonía Somers. Tesis doctoral. Universitat Autònoma de Barcelona, 2010. Web. 15 Jul. 2020.

Deleuze, Gilles y Félix Guattari. Mil mesetas. Capitalismo y esquizofrenia. Trad. José Pérez Vázquez y Umbelina Larraceta. Valencia, Pretextos, 2004. Impreso. 
Derrida, Jacques. "Carta a un amigo japonés". El tiempo de una tesis: Deconstrucción e implicaciones conceptuales. Trad. Cristina de Peretti. Barcelona, Proyecto A Ediciones, 1997, pp. 23-27. Impreso.

. De la gramatología. Trad. Oscar del Barco y Conrado Ceretti. México D. F., Siglo XXI editores, 1986. Impreso.

"El cartero de la verdad". La tarjeta postal. De Sócrates a Freud y más allá. Trad. Haydée Silva. México D. F., Siglo XXI editores, 1975, pp. 304-366. Impreso.

El libro del pueblo de Dios. La Biblia. Buenos Aires, Editorial San Pablo, 1996. Impreso.

Femenías, María Luisa. "Armonía Somers: la difícil andadura de una obra". Orbis Tertius, vol. 8, no. 9, 2002-2003, pp. 141-160. Web. $15 \mathrm{Jul} .2020$.

Foucault, Michel. Vigilar y castigar. Nacimiento de la prisión. Trad.ucción de Aurelio Garzón del Camino. Buenos Aires, Siglo XXI editores, 2002. Impreso.

Irigaray, Luce. Espéculo de la otra mujer. Trad. Raúl Sánchez Cedillo. Madrid, Editorial Akal, 2007. Impreso.

Kristeva, Julia. "Bajtín, la palabra, el diálogo y la novela". Intertextualité. Francia en el origen de un término y el desarrollo de un concepto. Trad. Desiderio Navarro. La Habana, UNEAC Casa de las Américas, 1997, pp. 1-24. Impreso.

Lacan, Jacques. "El estadio del espejo como formador de la función del yo (je) tal como se nos revela en la experiencia psicoanalítica". Escritos 1. Trad. Tomás Segovia. México, D. F., Siglo XXI, editores 2003, pp. 86-93. Impreso.

Seminario III: las psicosis (1955-1956). Trad. Juan Luis Delmont-Mauri y Diana Silvia Rabinovich. Buenos Aires, Paidós, 2009. Impreso.

Lorio, Natalia. "Plasticidad de las formas o cartografía del deseo. Una lectura de La mujer desnuda de Armonía Somers". El taco en la brea, no. 11, 2020, pp. 143-152. Web. 15 Jul. 2020.

Mailhe, Alejandra. "Cuerpo fantástico e identidad de género en dos ficciones de Armonía Somers”. Serie Monográfica, vol. 1, no. 1, 1997, pp. 87-108. Web. 15 Jul. 2020.

Montoro Martínez, Noelia. "La mujer desnuda: metamorfosis por decapitación". Anales de Literatura Hispanoamericana, no 34, 2005, pp. 217-234. Web. 15 Jul. 2020. 
Pateman, Carole. El contrato sexual. Trad. María Luisa Femenías, revisada por María-Xosé Agra Romero. Barcelona, Anthropos, 1995. Impreso.

Platón. "Timeo". Obras completas de Platón. Tomo 6. Ed. Patricio Azcárate. Madrid, Biblioteca Filosófica, 1872, pp. 129-264. Impreso.

Somers, Armonía. "La mujer desnuda". Clima. Cuadernos de Arte. Oct.Dic. 1950, pp. 73-126. Impreso.

Warner, Michael. Fear of a queer planet: Queer politics and social theory. Minneapolis, University of Minnesota Press, 1993. Impreso. 